\title{
Priming effects in attentional gating
}

\author{
JAMES F. JUOLA, PRATHYUSHA DUVURU, and MATTHEW S. PETERSON \\ University of Kansas, Lawrence, Kansas
}

\begin{abstract}
Three experiments were conducted to determine the effects of amount of prior target information (Experiment 1) and semantic priming (Experiment 2) in an attentional gating task. The goal was to determine some causes of the processing deficits commonly observed in perceiving successive visual stimuli. Items in a rapid serial visual presentation (RSVP) stream are subject to processing deficits before they are processed to the level of recognition (early selection) and after they have been recognized (late selection). Deficits in the former case presumably are due to an early filter that prevents complete recognition and semantic analysis, whereas deficits in the latter case arise from interference or response competition, producing forgetting among a set of recognized items. The semantic-priming effects found between a cue and a target (Experiment 2) and between two successive targets (Experiment 3) indicate that top-down processes can increase the subjective availability of related items. The results are consistent with the idea that most processing deficits observed in search through an RSVP sequence are due to limited capacity in our ability to form episodic representations of all the items in the sequence.
\end{abstract}

Attention is a term used to describe the distribution of resources over different channels of the human informationprocessing system (James, 1890; LaBerge, 1995). In visual attention, resources are distributed over both space and time, and sudden onsets and other salient changes in the visual scene can attract processing resources rapidly (Juola, Koshino, \& Warner, 1995; Yantis \& Jonides, 1990). Similarly, one's goals and expectations can also influence attention and perception (Posner, Snyder, \& Davidson, 1980; Theeuwes, 1996), as can contextual constraints (Biederman, Glass, \& Stacy, 1973; Palmer, 1975). Researchers' interests in spatial and temporal interactions among visual stimuli have changed from an initial focus on rather abstract masking and integration tasks (e.g., Breitmeyer \& Ganz, 1976; Eriksen \& Collins, 1969) to a focus on more ecologically valid tasks, such as processing visual scenes and reading passages of text (e.g., Juola, 1988; Loftus \& Mackworth, 1978).

Attention has been studied in laboratory tasks that tax observers' abilities to detect, identify, and describe brief visual stimuli (Engle, 1971; Posner, 1980; Sperling, 1960; von Wright, 1972). Improvements in performance for selected parts of a display can be demonstrated by the effects of spatial cues. Spatial cuing has been shown to be effective in detection, localization, and identification tasks,

This research was supported in part by a grant from the General Research Fund of the University of Kansas to the first author. We acknowledge the assistance of Jason D. Arndt, Charlotte A. Collins, Marci A. Flanery, and Kimberly Rials in Experiments 1 and 2 and Emily M. Charley and Erin McDermott in Experiment 3. We also thank Marvin Chun, Timothy McNamara, Kimron Shapiro, and Adam Reeves for helpful comments on an earlier version of this paper. Correspondence concerning this article should be addressed to J. F. Juola, Department of Psychology, University of Kansas, Lawrence, KS 66045 (e-mail: juola@lark.cc.ukans.edu). including visual search (Egly \& Homa, 1991; Juola, Bouwhuis, Cooper, \& Warner, 1991; Posner, 1980; van der Heijden, 1992). Such cues have definite time courses, over which they exert facilitatory and inhibitory effects on the processing of objects in the visual field (Cheal \& Lyon, 1991; Müller \& Rabbitt, 1989). Time courses of priming and masking effects also have been studied in a variety of paradigms, using stimuli varying from simple flashes to complex patterns, such as words in a text. These laboratory tasks are most relevant to natural behaviors, such as integrating information across successive eye movements in visual scene exploration and in focused tasks, such as reading (Juola, 1988; Rayner, 1983). The present set of experiments deals mainly with priming in sequential tasks that resemble reading in many of their basic features (Juola, Ward, \& McNamara, 1982).

Attentional limitations in processing sequential visual inputs have been found in a variety of experiments using the rapid serial visual presentation (RSVP) technique. In a typical RSVP task, participants are to report one or more targets that are differentiated in some way(s) from other items in the sequence. Errors in such tasks follow systematic patterns, forming the basis for theories of target feature analysis and integration along the temporal dimension. Despite the lack of conclusive evidence indicating how target-defining and response features are processed (e.g., serially or in parallel), the importance of attention in combining visual features is well established (Gathercole \& Broadbent, 1984; Treisman \& Gelade, 1980). Directing attention to a specific target has been shown to disrupt processing of items that follow it within about $500 \mathrm{msec}$ (Broadbent \& Broadbent, 1987; Raymond, Shapiro, \& Arnell, 1992). This deficit consistently occurs in tasks requiring the detection or identification of two or more targets. Models attempting to explain this posttarget processing deficit generally fall into two broad classes that 
correspond to traditional early- and late-selection theories of attention. The purpose of the present research is to gain a better understanding of mechanisms that underlie posttarget processing deficits in RSVP tasks.

Broadbent and Broadbent (1987) were among the first to report the interfering effect of identifying one target on the processing of a later one. Their participants were to identify two target words defined by either physical features or category membership. Successive words were presented at rates of 80 or $120 \mathrm{msec} / \mathrm{item}$, and the number of intervening words between targets was varied. They found that correct identification of the first target (T1) impaired identification of the second target (T2) if it occurred within about $500 \mathrm{msec}$ of $\mathrm{T} 1$, and that, within this interval, correct $\mathrm{T} 2$ identifications increased steadily with increases in the temporal interval between targets. They interpreted the results in terms of a two-stage, detectthen-identify model (Broadbent, 1977). In the first stage, observers scan the series of items to detect the targetdefining feature, and once the target is detected, it enters a limited-capacity second stage, at which it is identified. They argued that it is the attention-demanding process of identification that is responsible for impaired processing of subsequent items.

Using a slightly different procedure involving two streams of items, Reeves and Sperling (1986) observed similar posttarget deficits. They asked participants to monitor an RSVP stream presented to the left of fixation for the presence of a predefined cue letter. On detecting the cue, participants were to shift their attention to a digit stream presented to the right of fixation and report the earliest visible numeral. Typically, the numeral reported occurred about $300 \mathrm{msec}$ after the cue, although there was considerable spread across positions. The average time delay between cue onset and the onset of the reported digit was taken as a measure of attentional reaction time (ART), which is the time needed to identify the cue in the letter stream, shift attention to the numeral stream, and then identify the first visible numeral. Weichselgartner and Sperling (1987) found deficits in reporting posttarget items even when shifting attention to a different location was not required. In their study, a single stream of digits was presented, and observers were to identify the first four items following a cue (an outline square around one of the digits). Most of the digits recalled occurred either between 0 and 100 or between 300 and $400 \mathrm{msec}$ after the cue. They proposed the operation of two consecutive, partially overlapping attentional processes. One is a fast, automatic process, triggered by cue detection, that is responsible for identification of the cue and the item following it. The second is a slower, controlled process that is responsible for identification of numerals appearing about $300 \mathrm{msec}$ after the cue.

In an attempt to understand whether posttarget processing deficits are due to memory, attentional, or sensory factors, Raymond et al. (1992) modified the procedures used by Broadbent and Broadbent (1987) and Weichselgartner and Sperling (1987). Participants in their study viewed a single stream of black letters and were to identify a target letter appearing in white and then to detect the presence or absence of a T2 (probe), which was always the black letter $\mathbf{X}$. In a control condition, participants were to ignore the target and merely detect the probe. The probe was present on $50 \%$ of the trials, and the number of intervening items between the target and the probe was varied between zero and seven. Relative to the control condition, in which probe detection was uniformly high, participants who were required to identify the target showed a significant deficit in probe detection when it occurred between 180 and $450 \mathrm{msec}$ after the target. Even though both groups received the same sensory information, the probe detection deficit occurred only when the target was to be identified, suggesting that the temporary impairment in visual processing was due mainly to attentional, rather than to sensory, limitations. This temporary deficit in visual processing resulting from attentional limitations has been termed the attentional blink (AB; Raymond et al., 1992).

There are different views about when during processing the $A B$ occurs. One important difference is whether the deficit occurs before or after target identification, which corresponds to traditional early- and late-selection theories of attention. The inhibitory model proposed by Raymond et al. (1992) is similar to Weichselgartner and Sperling's (1987) and explains the $A B$ in terms of a gate that filters out posttarget items before they can be identified. In their model, if the item following the target ( $\mathrm{T}+1$ item) appears before target identification is complete, it leads to interference with target processing. To prevent further interference, a suppressive mechanism blocks processing of subsequent items until the target is identified. The finding that replacing the $\mathrm{T}+1$ item with a blank field almost eliminated the $A B$ was taken as support for this model. However, the inhibitory model is incompatible with results such as the finding that a reduction in target identification difficulty does not always influence the magnitude of the AB deficit (Shapiro, Raymond, \& Arnell, 1994).

A second explanation for the $A B$ is the interference model (Shapiro et al., 1994), adapted from Duncan and Humphreys's (1989) similarity theory. Following the initial representation of each item in the stream, items that closely match internal templates for the target and the probe are selected for entry into a visual short-term memory (VSTM). By virtue of being temporally contiguous to the target and probe, items that immediately follow them can also gain entry into VSTM. It is interference among these items in VSTM that leads to failure in detecting the probe. Since the target is usually the first item in the stream to match the target template closely, it is entered into VSTM with high probability. The target is also subject to relatively little interference, unless it is highly similar to the distractors. The subsequent probe suffers a different fate, especially if it follows closely on the heels of the target. Even if the probe is selected for entry into the VSTM, it is not guaranteed the level of detailed processing afforded the target, because it must 
compete for limited resources with the target and, possibly, other items already in the VSTM. This model suggests that the greater the similarity among items in the VSTM, the greater their mutual interference, resulting in a reduced probability of retrieving the probe item. When, in fact, the $\mathrm{T}+1$ item is featurally dissimilar to the rest of the items in the stream, the magnitude of the $A B$ has been found to be significantly attenuated, even though deficits in probe detection remain (Raymond, Shapiro, \& Arnell, 1995).

Chun and Potter (1995; see also Chun, 1997) also explained the $\mathrm{AB}$ in terms of a two-stage model somewhat similar to that of Broadbent and Broadbent (1987). According to Chun and Potter's model, almost every item in an RSVP stream undergoes Stage 1 processing, in which stimulus identity becomes available briefly. However, these representations are subject to rapid decay unless they are processed further (consolidated) in Stage 2. This second stage has limited capacity, which forces items to be processed serially. When the duration of $\mathrm{T} 1$ processing in Stage 2 exceeds the time interval between T1 and T2, $\mathrm{T} 2$ can be prevented from entering Stage 2 and, thus, is lost from memory. That is, if T2 is not processed beyond Stage 1 because second-stage processing of $\mathrm{T} 1$ is incomplete when T2 occurs, its initial representation is subject to rapid forgetting and is not reported.

Chun's (1997) extension of the two-stage model (Chun \& Potter, 1995) explains the AB in a type-token framework. He argues that the $\mathrm{AB}$ results from failure to bind an item's activated type to its token. That is, the target's features processed in Stage 1 lead to activation of the target's type code as part of the recognition process. In order for the item to be reported, the activated type representation must be linked to its specific token, a process Chun calls tokenization. The linking of an activated type to a particular token experience is a limited-capacity process that occurs in Stage 2. Tokenization is more likely to be completed rapidly and correctly when a target's features are dissimilar to those of the distractors (see Chun \& Potter, 1995). Presentation of an item immediately after T1 interferes with tokenization of the target, because encoding of $\mathrm{T}+\mathrm{l}$ 's features decreases the signal-to-noise ratio of target to distractor type codes, especially if their features are similar.

According to the detect-then-identify (Broadbent, 1977), attentional gating (Weichselgartner \& Sperling, 1987), and inhibition models (Raymond et al., 1992), the $\mathrm{AB}$ results from a limited-capacity system that is capable of processing little, if any, information from subsequent items until the $\mathrm{Tl}$ is identified. These models are based on an early-selection notion of attention. In contrast, the basis for the two-stage (Chun \& Potter, 1995) and interference models (Shapiro et al., 1994) is a late-selection view of attention. The two-stage model places the $A B$ deficit in the tokenization stage, which is responsible for binding an object's type codes in the first stage into a coherent whole. The interference model proposes that the $\mathrm{AB}$ occurs after complete identification of both targets and it attributes the deficit to difficulty in retrieving the target and probe (or T2) from the VSTM that is due to interference among them and other, especially adjacent and similar, items in the RSVP stream.

The present experiments were designed to gain a more complete understanding of the mechanisms responsible for sequential processing deficits, such as those observed in $\mathrm{AB}$ and attention-switching tasks, and to determine the level in visual information processing at which they occur. Unlike most of the previous studies, which used letters or digits as stimuli, we used words in all the experiments. Both the physical and the semantic characteristics of the target words were manipulated, to determine whether attentional deficits occur before or after meaning is accessed.

If increasing the semantic relatedness of two targets in an RSVP stream decreases the magnitude of the attentional deficit, it would be reasonable to assume that the deficit occurs later in visual processing, after semantic information from $\mathrm{T} 2$ has been accessed. Broadbent and Broadbent (1987) specifically compared the accuracy of target reports when two targets in an RSVP stream were semantic associates versus unrelated words and found no reliable difference. However, their experiment most probably lacked sufficient power to find such a difference, since Maki, Frigen, and Paulson (1997) replicated their design and found large priming effects on $\mathrm{T} 2$ report accuracy for items related to $T 1$ words, despite the fact that a large $\mathrm{AB}$ effect was found for both related and unrelated target pairs. In another experiment, Maki et al. reported that distractor words occurring between $\mathrm{T} 1$ and $\mathrm{T} 2$ could also prime $\mathrm{T} 2$, so that $\mathrm{T} 2$ items related to distractors occurring during the $\mathrm{AB}$ period improved the report probability for $\mathrm{T} 2$ items. Both results are consistent with the idea that an early attentional filter, if one exists, is sufficiently permeable to allow some semantic analysis of distractors or $\mathrm{T} 2$ items presented during the $\mathrm{AB}$ period (i.e., $500 \mathrm{msec}$ or so after T1; see also Shapiro, Driver, Ward, \& Sorensen, 1997). On the other hand, the results are consistent with two-stage or late-selection models, which assert that the $\mathrm{AB}$ is due to limited capacity or interference among identified items. Semantic priming of $\mathrm{T} 2$, from either $\mathrm{T} 1$ or an intervening distractor item, could provide top-down activation of $\mathrm{T} 2$ and increase its distinctiveness from competing items, thereby also increasing its report probability.

In the three experiments reported here, an attentional gating procedure, similar to that developed by Reeves and Sperling (1986), that involved two streams of stimuli was used. The items to be attended and/or reported occurred either in the same stream or in different streams, in order to assess whether the additional requirement of attention shifting adds anything to the $\mathrm{AB}$ effect. Items to be reported in the two streams were either unrelated or related pairs of words. The consistent priming effects that we observed are discussed in terms of existing models of the $\mathrm{AB}$ that represent different views about the locus and processing mechanisms responsible for the $\mathrm{AB}$ deficit. 


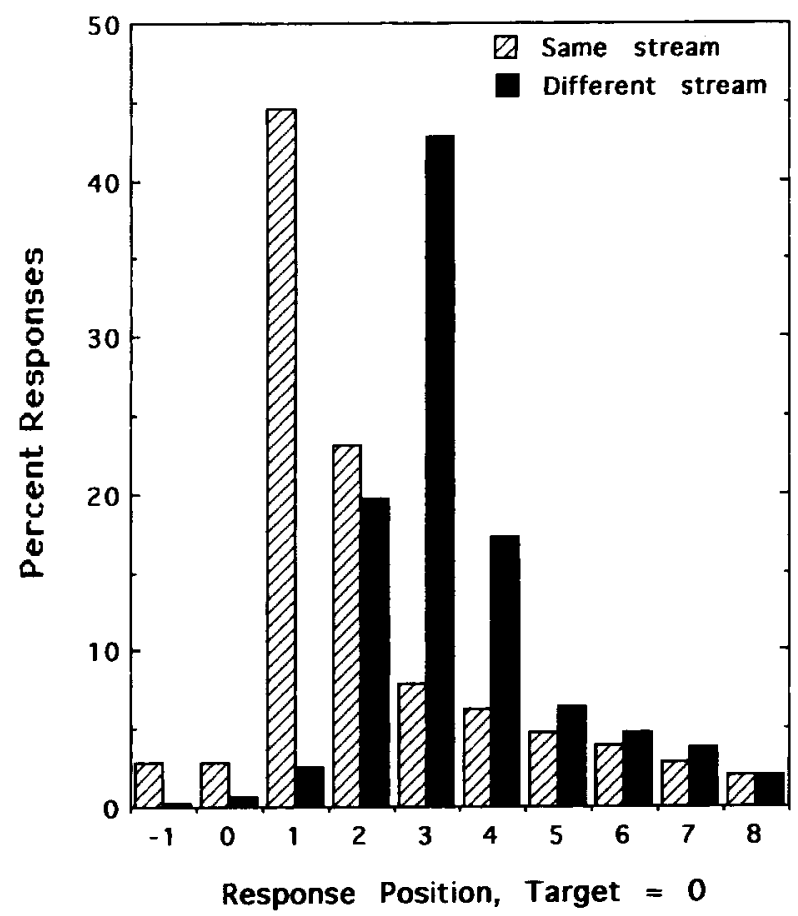

Figure 1. Distribution of mean percent of responses across serial positions of the rapid serial visual presentation stream in Experiment 1. The target appeared in Position 0 of the upper stream, and participants were to report the word presented after the target in the same stream or in the one below it (different stream).

\section{EXPERIMENT 1}

Research has suggested that the attention-demanding process of target identification is responsible for the $A B$ (Broadbent \& Broadbent, 1987; Chun \& Potter, 1995; Raymond et al., 1992). In the first experiment, we tested this idea by manipulating the kind and amount of advance information given about the target. If the limited-capacity process of target identification is responsible for posttarget perceptual deficits, these deficits should be reduced as targets are made more salient by increasing the amount of pretrial information specified about them. The method used here was similar to the attention gating paradigm of Reeves and Sperling (1986). The participants were presented with two streams of words, one above the other, and their task was to detect the target, which always appeared in the upper stream, and then to report the word appearing immediately after the target. In separate trial blocks, the to-be-reported word was either in the same (upper) stream as the target or in the stream below the target. Weichselgartner and Sperling (1987) reported a bimodal response tendency in same-stream trials, but not in different-stream trials, which could indicate the presence of different aspects of the $A B$ when attention is maintained in one position versus being shifted to another after detecting $\mathrm{T} 1$.

\section{Method}

Participants. Eleven students ( 6 males and 5 females) from the University of Kansas participated as part of a course requirement. The participants had normal or corrected-to-normal visual acuity.

Apparatus. Stimulus presentation was controlled by a Macintosh Quadra 610 computer, with a Sony Trinitron cathode ray tube ( 2.66 pixels per $\mathrm{mm}$ ) being used to display the stimuli. The participants viewed the display from a distance of about $60 \mathrm{~cm}$ and responded verbally.

Stimuli and Procedure. The stimuli consisted of 3,600 of the most common four- to seven-letter words in English, selected from Kučera and Francis (1967). They extended about $1.0^{\circ}-1.7^{\circ}$ of visual angle from a viewing distance of about $60 \mathrm{~cm}$. There was a total of 120 trials, which were divided into two blocks of 60 trials each. In each trial, the participants were presented with two streams of words, one above and one below a fixation point. The streams were separated by $0.8^{\circ}$ of visual angle. Each stream consisted of 15 words chosen randomly from the complete stimulus list, with the constraint that no word was presented more than once to any participant. Words other than the target always appeared in lowercase. The items were presented at the rate of $120 \mathrm{msec} /$ word, with no interstimulus interval (ISI) between them.

To start each trial, the target was defined by a cue in one of three different ways. In the form-only condition, the cue was a row of uppercase Xs, and the participants were told that the target would appear in uppercase letters in the upper stream. In the identity-only condition, the target was shown in lowercase letters before the trial, and the participants were told that the target would appear in the same lowercase font in the upper stream. In the form-plus-identity condition, the target word was shown before the trial in uppercase, and it appeared the same way in the upper stream. The target was randomly assigned to Serial Positions 4-7 in the RSVP stream.

Each trial began with the presentation of a cue at the center of the screen, indicating how the target would be defined on that trial. The cue was displayed for $750 \mathrm{msec}$, followed by a pair of masks (seven pound signs: \#\#\#\#) indicating where the two streams would appear, which were also displayed for $750 \mathrm{msec}$. The masks appeared above and below a fixation point that replaced the target cue. They were then followed by the presentation of the two RSVP streams. There were two different blocks of trials. In one of the blocks, the participants were instructed to detect the target word, which always appeared in the upper stream, and then to report the word presented immediately after the target in the same stream (same-stream condition). In the other block, the participants were asked to switch their attention immediately after detecting the target and report the first word seen in the lower stream (different-stream condition). The participants were given 20 practice trials, using materials similar to those used in the experimental trials, prior to the beginning of each block. The order of the two blocks was determined randomly. The participants reported their responses verbally, and these were recorded by the experimenter.

\section{Results and Discussion}

The mean percentage of times that a word anywhere in the stream was given as the response is plotted as a function of its serial position relative to that of the target (Position 0 ) for both the same- and the different-stream conditions (see Figure 1). These data are collapsed across the three target definition conditions. The modal response tendency differed greatly between conditions: In the same-stream condition, $44 \%$ of the responses were from the +1 position whereas in the different-stream condition, $43 \%$ of the responses were from the +3 position. 
Table 1

Mean Response Position Under Different Types of Target Specifications for Same and Different Rapid Serial Visual Presentation Stream Conditions in Experiment 1

\begin{tabular}{lccc}
\hline \multicolumn{1}{c}{ Condition } & Form Only & Identity Only & Form + Identity \\
\hline Same stream & 3.06 & 1.67 & 1.74 \\
Different stream & 3.38 & 3.45 & 3.12 \\
\hline
\end{tabular}

Note-Response position $\times 120 \mathrm{msec}$ (stimulus onset asynchrony) $=$ mean response time.

Table 1 shows the mean position of responses given under all three cue types (form only, identity only, and form plus identity) for both the same- and the differentstream conditions. Approximate attentional response times were computed by multiplying the mean response position in each condition by the time of stimulus presentation $(120 \mathrm{msec})$. These response times were longer in the different-stream condition than in the same-stream condition by an average of $139 \mathrm{msec}$. Response times were shortest in the form-plus-identity condition, followed by the identity-only condition, and the form-only condition.

A 2 (stream type) $\times 3$ (cue type) repeated measures analysis of variance (ANOVA) of the data for mean position reported revealed significant main effects for stream type $\left[F(1,10)=81.6, M S_{\mathrm{e}}=0.27, p<.05\right]$ and cue type $\left[F(2,20)=20.5, M S_{\mathrm{e}}=0.19, p<.05\right]$ and a significant interaction between stream and cue types $[F(2,20)=14.6$, $\left.M S_{\mathrm{e}}=0.21, p<.05\right]$. The difference in mean response positions between the same-stream and the differentstream conditions was less when the targets were defined in terms of only a physical feature (form only) than when they were defined in terms of their identity (identity only and form plus identity). It appears that knowing the identity of the target speeded responses for the same-stream condition only; there was little difference among the three cue conditions for different-stream trials.

The results of Experiment 1 are consistent with Reeves and Sperling's (1986) findings. In the different-stream condition, the word appearing $360 \mathrm{msec}$ after the target was most likely to be reported. Converting the mean response position to milliseconds resulted in a targetresponse delay of $398 \mathrm{msec}$ for different-stream trials. This is comparable with the $400 \mathrm{msec}$ ART reported by Reeves and Sperling, which is the time needed to detect the cue, shift attention from one stream to another, and identify the earliest possible target. In the present study, the difference in mean response times for same-stream and differentstream trials was $139 \mathrm{msec}$, which perhaps is a better estimate of the actual time necessary to switch attention from the upper stream to the lower one.

Overall, in the same-stream condition, the item immediately following the target was most likely to be reported correctly. This result is consistent with findings that $\mathrm{T} 2$ is more likely to be reported correctly if it appears in the $\mathrm{T}+1$ position, rather than later in the stream (Chun \& Potter, 1995; Raymond et al., 1992), because the target and the item following it often are unavoidably processed together. However, the results show that the distribution of responses over words following the target is influenced by type and degree of target definition and by the processing demands of target identification. This result is compatible with both the two-stage model (Chun \& Potter, 1995) and the interference model (Shapiro et al., 1994). Knowledge about the target could prime the target's type codes or features, leading to more rapid processing and quicker reallocation of resources to process later items.

When the target was defined only in terms of its physical features, the word reported generally occurred later in the stream than it did when the target's identity was known in advance, at least for same-stream trials. It is likely that knowing the target's-identity eliminated the target as a response candidate. When its identity was unknown, however, as in the form-only condition, the identity of the capitalized word could have competed with those of the following word(s), producing greater interference and, thereby, greater uncertainty and delay in choosing a response. In the different-stream condition, the target could not possibly be a response candidate, so any interference effects should be equal across all three target cue conditions. It is also likely that the speed at which attention can be switched to a new spatial location is slower than the speed of target detection. In that case, the responsedetermining factor in the different-stream condition could be attention-switching speed and not target identification time. Likewise, since attention was not switched to a new spatial position in the same-stream condition, the mean response position was mainly dependent on how quickly target processing could be completed.

\section{EXPERIMENT 2}

In Experiment 1, the extent of the posttarget deficit was found to be related to the processing demands of the target detection task. Detecting an unknown target led to a greater deficit in processing items than did detecting a prespecified target, at least for same-stream trials. These results support the inhibition model (Raymond et al., 1992) and the two-stage model (Chun \& Potter, 1995), in which target identification processes tie up limited resources, temporarily reducing the amount of processing available for items appearing subsequent to the target. In Experiment 2, we examined the type of processing deficits that posttarget items endure by manipulating the semantic relationship between the target and one of the items following it.

In Experiment 2, the target was followed by a high semantic associate on two thirds of the trials in one of four serial positions. If $T+1$ items are not processed at all until target identification is complete, the mean response position should be similar in prime and no-prime conditions. Any difference in mean response positions between these conditions would suggest that items closely following the target receive sufficient processing to activate a semantic representation in memory. As in Experiment 1, 


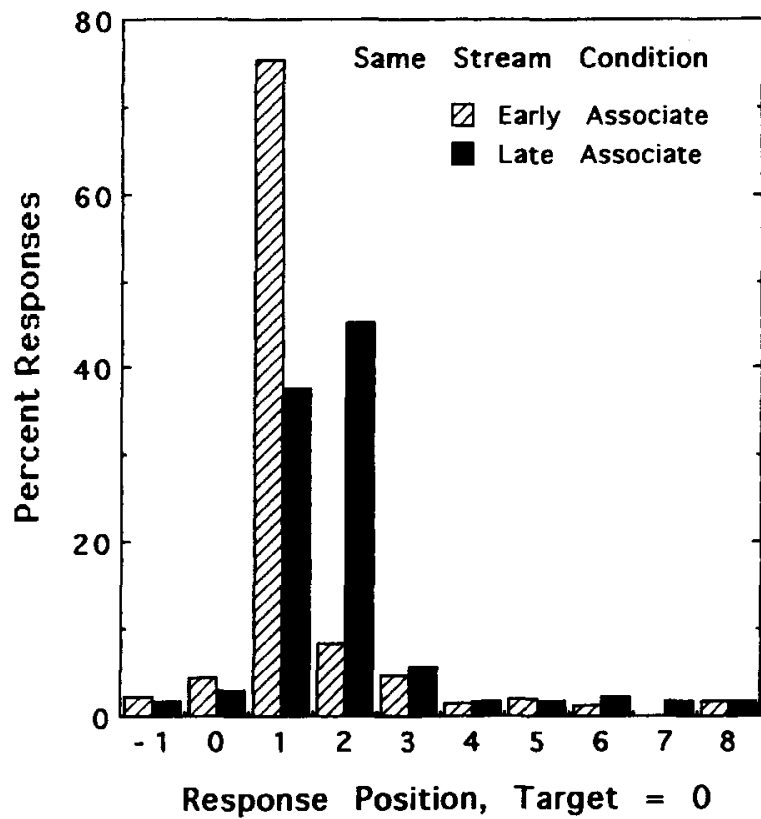

Figure 2. Distribution of mean percent of responses across serial positions of the rapid serial visual presentation stream for the same-stream condition of Experiment 2. The target appeared in Position 0, and a high associate of the target appeared in Position 1 (early associate) or in Position 2 (late associate).

targets were defined in one of three ways (form only, identity only, or form plus identity), and they always appeared in the upper stream.

\section{Method}

Participants. Twenty-nine students (14 males and 15 females) from the University of Kansas participated.

Apparatus. The apparatus was the same as that used in Experiment 1 .

Stimuli and Procedure. As in Experiment 1, there were two stream conditions (same and different streams) and three different ways in which targets were defined (cue types: form only, identity only, and form plus identity). On two thirds of the trials, a semantic associate of the target was placed in one of four serial positions after the target. In the early-associate condition, the associate was placed in Serial Position 1 (same stream) or 2 (different stream) after the target, and in the late-associate condition, it was placed in Position 2 (same stream) or 4 (different stream). These positions were chosen to bracket the mean positions reported in the same- and differentstream conditions in Experiment 1 . There were two experimental blocks of 60 trials each.

The targets and their semantic associates were chosen from Nelson, McEvoy, and Schreiber's (1993) associative norms. All the semantic associate pairs used in early- and late-associate conditions had an associative strength of over .5 (i.e., each of the associates was given as the response to the stimulus word by at least $50 \%$ of the normative sample). The distractor words in the stream were selected randomly from the same pool that was used in Experiment 1.

\section{Results and Discussion}

Mean percentage of responses as a function of relative serial position of the word given as a response is plotted for early-associate and late-associate conditions in Fig- ures 2 and 3 . When the target was followed by its associate (early-associate condition) in the same-stream condition, the percentage of trials on which this item was given as the probe response was considerably higher $(75 \%)$ than in Experiment $1(45 \%)$. In the different-stream condition, the modal response position of the probe moved from Serial Position 3 in Experiment 1 to Position 2 in the present experiment when the target was followed by an early associate. Figure 4 shows the mean response positions of words reported as probes under all three cue types and two associate positions. As in Experiment 1, response times can be computed by multiplying mean response position by the presentation time per word $(120 \mathrm{msec})$.

A 2 (stream) $\times 3$ (cue type) $\times 3$ (prime type) repeated measures ANOVA revealed significant main effects for stream $\left[F(1,21)=223.04, M S_{\mathrm{e}}=1.03, p<.05\right]$, cue type $\left[F(2,42)=32.45, M S_{\mathrm{e}}=0.43, p<.05\right]$, and prime type $\left[F(2,42)=27.17, M S_{\mathrm{e}}=0.46, p<.05\right]$ and a significant stream $\times$ cue type interaction $\left[F(2,42)=4.78, M S_{\mathrm{e}}=0.39\right.$, $p<.05$; see Table 2].

The pattern of response times under the three different cue types was similar to the one found in Experiment 1, with responses being slowest in the form-only condition and fastest in the form-plus-identity condition. Also, the difference in mean response times between the same- and the different-stream conditions was less in the form-only condition than in the other two conditions, as was found in Experiment 1.

The results of Experiment 2 suggest that the attentiondemanding process of target identification does not cause

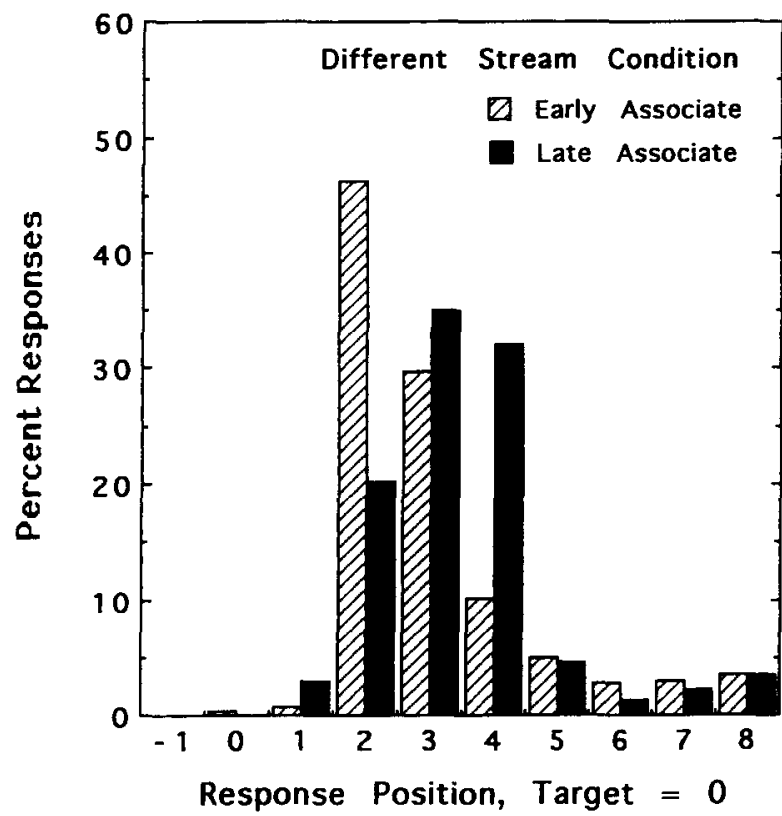

Figure 3. Distribution of mean percent of responses across serial positions of the rapid serial visual presentation stream for the different-stream condition of Experiment 2. The target appeared in Position 0 , and a high associate of the target appeared in Position 2 (early associate) or in Position 4 (late associate). 


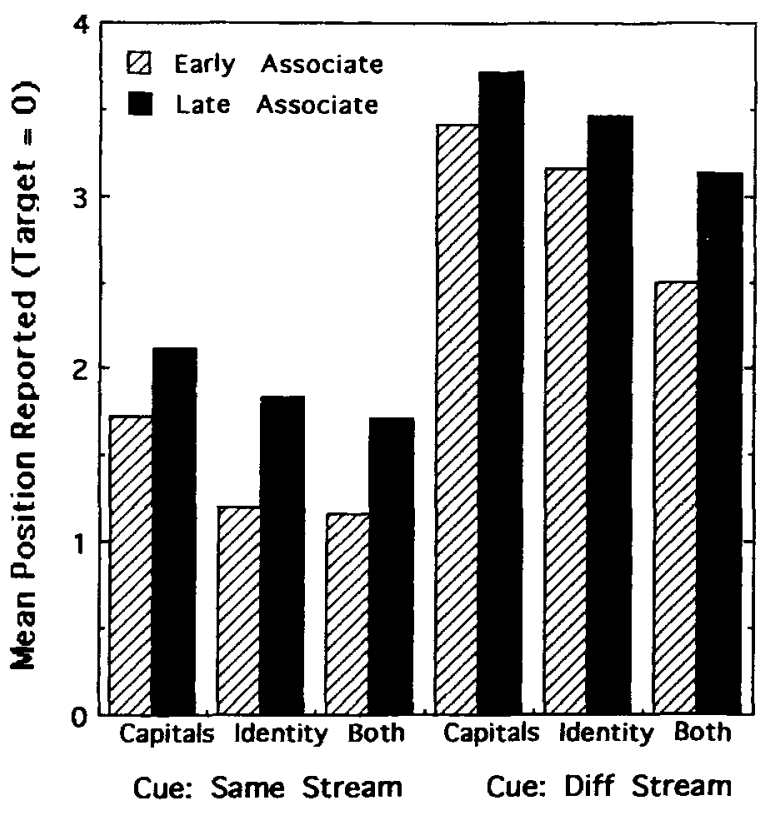

Figure 4. Mean position reported after the target (Position 0) for the early- and late-associate conditions for same- and different-stream trials of Experiment 2. The data are plotted separately for the three levels of target information given before the trial.

deficits in reporting posttarget items by filtering them out at an early level of processing, since $T+1$ items were more likely to be reported if they were associated with the target than if they were not. If items immediately following the target were not processed at all until target identification was complete, the mean response position should have been similar in the early- and the no-associate conditions. In fact, the mean position reported decreased by .73 , or $87 \mathrm{msec}$, for early-associate conditions in the same-stream condition and by .43 , or $52 \mathrm{msec}$, for early associates in the different-stream condition, indicating that top-down activation can operate on some representations of posttarget items to improve their response selection probability. If they had been completely suppressed by an early-selection filter, such associative priming from the target should have had no effect. Of course, a leaky early-selection filter could allow enough sensory information to pass through for the representation to benefit from top-down priming. Also, an early-selection filter might not be activated immediately, and the $\mathrm{T}+1$ item might be processed with the target. In fact, the inhibition theory is based on the assumption that it is the $T+1$ item that activates the suppressive mechanism (Raymond et al., 1992). However, early associates also resulted in an earlier mean report position on different-stream trials, which involved words presented two positions after the target. This result indicates that, even if it is the $T+1$ item that initiates a suppressive filter, subsequent items can still be primed by related target words. Such a filter, then, would only attenuate deeper processing of posttarget words. On the other hand, there was very little effect of the late- associate condition relative to the no-associate control. Apparently, once a word has been selected for a response, an associatively primed later word has little chance of displacing it as a response choice.

\section{EXPERIMENT 3}

The third experiment was designed to trace the relationship between priming and the $\mathrm{AB}$ more precisely by varying the lag between two target words ( $\mathrm{T} 1$ and $\mathrm{T} 2$ ) that could appear in either the same or different streams. If the $A B$ is determined by some type of early filter that prevents processing of words after T1, priming effects should be minimal while $T 1$ is being processed and should increase as the early filter is attenuated. That is, the inhibition model predicts an interaction between priming effects and a T1-T2 lag. On the other hand, if the AB is mainly due to interference among competing response choices in the VSTM, associative priming effects should be relatively independent of the lag between $\mathrm{T} 1$ and $\mathrm{T} 2$ (see Maki et al., 1997). Finally, if the same type of attentional processes operate in same- and different-stream tasks, priming effects should be similar across tasks.

\section{Method}

Participants. Twenty-five students (11 males and 15 females) from the University of Kansas participated in exchange for course credit.

Design. Four variables were crossed in a within-subjects factorial design: single-stream versus dual-stream tasks ( $\mathrm{T} 1$ and $\mathrm{T} 2$ were in the same or different streams), priming ( $\mathrm{T} 1$ and $\mathrm{T} 2$ were high associates of each other or were unrelated), validity of the positional cue (the stream location of T1 was cued validly on $90 \%$ of the trials, whereas T2 location cues were $100 \%$ valid), and lag (the number of items intervening between $\mathrm{T} 1$ and $\mathrm{T} 2$, which varied from zero to four). These factors produced a $2 \times 2 \times 2 \times 5$ repeated measures design with nine validly cued $\mathrm{T} 1$ positions and one invalidly cued $\mathrm{T} 1$ position in each stream $\times$ priming $\times$ lag condition, yielding a total of 200 trials per participant.

Stimuli. The distractor words were chosen from the same pool of words as that used in Experiments 1 and 2. Associated target pairs were selected from the Nelson et al. (1993) norms, and all had an associative strength of .53 or higher. On low-association trials, $\mathrm{T} 1$ was replaced with one of the distractor items. Both targets were differentiated from distractors by being presented in all uppercase

Table 2

Mean Response Position Under Early-, Late-, and No-Associate Conditions for Same and Different Rapid Serial Visual Presentation Stream Conditions in Experiment 2

\begin{tabular}{lccc}
\hline Condition & Form Only & Identity Only & Form + Identity \\
\hline $\begin{array}{l}\text { No associate } \\
\quad \text { Same }\end{array}$ & 2.69 & 1.91 & \\
$\quad$ Different & 3.52 & 3.72 & 1.67 \\
Early associate & & & 3.12 \\
$\quad$ Same & 1.73 & 1.20 & \\
$\quad$ Different & 3.41 & 3.16 & 1.16 \\
$\quad$ Late associate & & & \\
$\quad$ Same & 2.12 & 1.83 & 1.71 \\
$\quad$ Different & 3.72 & 3.46 & 3.13 \\
\hline
\end{tabular}

Note-Response position $\times 120 \mathrm{msec}$ (stimulus onset asynchrony) $=$ mean response time. 


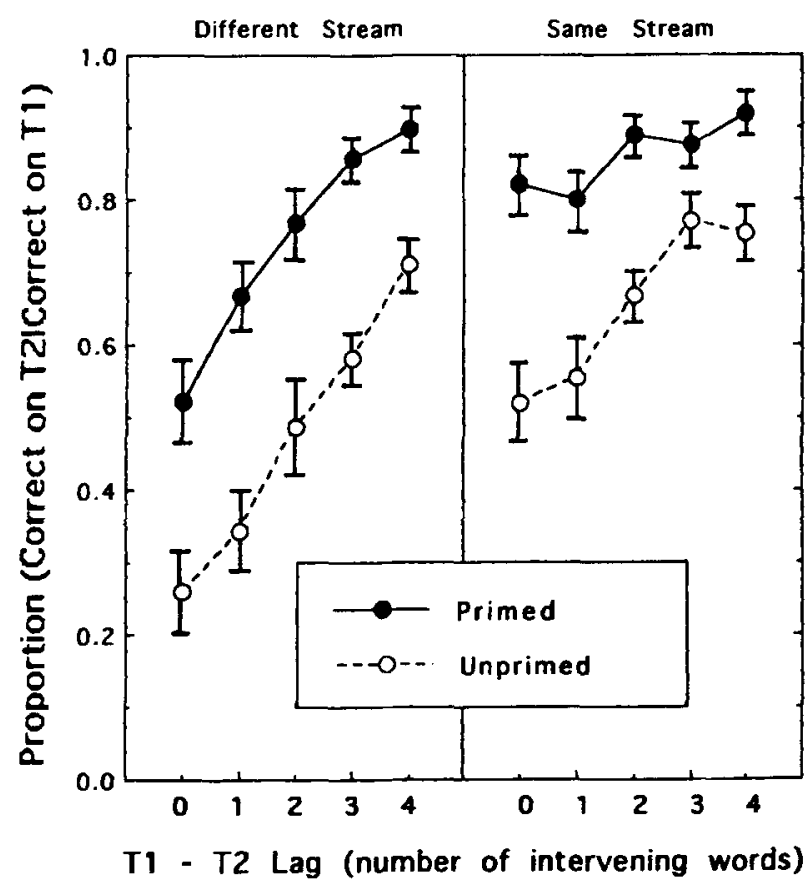

Figure 5. Proportion of correct second target (T2) identification detections, given correct first target (T1) identifications, as a function of the T1-T2 lag in Experiment 3. The data are plotted separately for primed and unprimed targets in same-stream and different-stream conditions. The error bars above and below each data point represent \pm 1 the standard error of the mean.

letters; distractors appeared in lowercase. The streams were presented above and below a central fixation point, as in the first two experiments. Each stream consisted of 19 words, and T1 occurred randomly in Positions 7-13. The T2 item occurred randomly in one of the five positions after $\mathrm{Tl}$ and either in the same stream or in the other stream. All the words were presented for $105 \mathrm{msec}$ each, with an ISI of $15 \mathrm{msec}$. (The addition of a small ISI seemed to improve the subjective clarity of words, as opposed to Experiment 1 and 2.)

Procedure. Each session began with 20 practice trials, followed by 200 experimental trials. Each trial used two streams, above and below the fixation point, as in the first two experiments. At the beginning of each trial, two colored rectangles were presented in succession for $750 \mathrm{msec}$ each. The first, red rectangle appeared in the stream position that would include $\mathrm{T} 1$ on $90 \%$ of the trials, and the second, blue rectangle appeared in the (same or different) stream position that would include T 2 on $100 \%$ of the trials. After the second rectangle cue, a fixation dot appeared for $450 \mathrm{msec}$, followed by the RSVP streams. The participants were to report the identities of the two target items, guessing if necessary, and these were recorded by the experimenter.

\section{Results and Discussion}

The analysis is limited to those $90 \%$ of the trials on which the T1 location cue was valid. The $10 \%$ invalid location cues were included to ensure that the participants maintained fixation between the two streams and were prepared for $\mathrm{T} 1$ in either stream.

Overall, about $91 \%$ of the T1 items were identified correctly, and $\mathrm{T} 1$ identifications were more accurate on primed trials $(93 \%)$ than when $\mathrm{T} 1$ and $\mathrm{T} 2$ were unrelated $\left[89 \% ; F(1,24)=15.36, M S_{\mathrm{e}}=0.02, p<.001\right]$. The proportion of $T l$ identifications also increased over the first few lags, with the mean proportions correct being equal to $.87, .89, .93, .92$, and .92 for $0-4$ intervening items between $\mathrm{T} 1$ and $\mathrm{T} 2$, respectively $\left[F(4,96)=8.16, M S_{\mathrm{e}}=0.01\right.$, $p<.001]$. There was also an interaction between lag and priming condition $\left[F(4,96)=2.69, M S_{\mathrm{e}}=0.01, p=\right.$ .035]; the lag effect was less pronounced for related $T 1$ and T2 words than for unrelated items. Overall, the T1 deficit at short lags is consistent with the interference (Shapiro et al., 1994) and two-stage (Chun \& Potter, 1995) models, since $\mathrm{T}+1$ items that are highly similar to it (i.e., another uppercase word -namely, T2) interfere with target identification. A similar result was reported by Broadbent and Broadbent (1987).

However, the data of main interest are the proportions of correct $\mathrm{T} 2$ reports conditionalized on correct $\mathrm{T} 1$ identification on the same trial. These data are shown in Figure 5 , in which the mean conditionalized proportions of correct T2 responses are plotted against T1-T2 lag for same-stream and different-stream conditions and for primed and unprimed conditions within each stream. The data show significant main effects for both prime $[F(1,24)$ $\left.=61.87, M S_{\mathrm{e}}=0.11, p<.001\right]$, and stream $[F(1,24)=$ $\left.32.12, M S_{\mathrm{e}}=0.09, p<.01\right]$, indicating that T2 identification was higher if it occurred in the same stream as T1 and, also, if $\mathrm{T} 1$ and $\mathrm{T} 2$ were associatively related. The interaction between prime and stream did not achieve significance $[F(1,24)=3.21, p=.086]$. These results are inconsistent with an early-filter theory that advocates suppressed processing of post-T1 items while $\mathrm{T} 1$ is being processed. If these items were suppressed, they should have been relatively immune to priming effects. On the other hand, if all items are processed to the level of recognition and entered into a short-term memory buffer, primed items might have greater activation levels, longer residence times in the buffer, or both, resulting in a greater likelihood of being selected as a response regardless of variations in lag, at least over the $600-\mathrm{msec}$ lag interval investigated here.

The main effect of lag was also significant $[F(4,96)=$ $\left.29.60, M S_{\mathrm{e}}=0.05, p<.001\right]$, as was the lag $\times$ stream interaction $\left[F(4,96)=6.18, M S_{\mathrm{e}}=0.04, p<.001\right]$. In general, the lag effect was greater in different-stream conditions than in same-stream conditions, which is mainly due to the fact that performance was much poorer in the different-stream condition at the short lags, whereas the stream effect disappeared at the longest lag. This result indicates that there is an $\mathrm{AB}$ effect limiting performance for $\mathrm{T} 2$ items that closely follow $\mathrm{T} 1$ and that this $\mathrm{AB}$ effect is even stronger when attention must be shifted from the $T 1$ stream to the $T 2$ stream than when both items appear in the same stream. Attentional shift effects apparently are absent after about $480 \mathrm{msec}$, indicating that attention to the T2 stream is, by then, independent of whether visual attention has shifted after T1 identification or not. 
No other effect, including the lag $\times$ prime $\times$ stream interaction, was significant in the data.

\section{GENERAL DISCUSSION}

The results from the present series of experiments using a common dual-stream RSVP task indicate that directing attention to one target in a stream of words interferes with the processing of later targets, replicating previous findings of posttarget processing deficits in sequential information processing (Broadbent \& Broadbent, 1987; Chun \& Potter, 1995; Raymond et al., 1992; Reeves \& Sperling, 1986; Weichselgartner \& Sperling, 1987). The major question addressed by all three experiments was whether such attentional deficits occur at an early stage of visual processing (e.g., during initial perceptual analysis or target detection) or at a later stage, after items have been fully recognized (e.g., during identification or retrieval). Different models of the $A B$ - such as the inhibition model (Raymond et al., 1992), the twostage model (Chun \& Potter, 1995), and the interference model (Shapiro et al., 1994) - vary in their assumptions about the locus of the $\mathrm{AB}$ and the mechanisms responsible for it.

In Experiments 1 and 2, we used a procedure similar to the attentional gating paradigm of Reeves and Sperling (1986). Two streams of words were presented, one above the other, and the task was to detect a target in the upper stream and then report the item after it from either the same stream or the stream below it. We manipulated the amount of target information given in advance and found that it was inversely related to the extent of the posttarget processing deficit. This relationship occurred even though participants were required merely to detect the target. It is possible that, despite the fact that identification was unnecessary in our task, the targets were identified and that this identification was facilitated by the amount of advance information. This finding is consistent with the inhibition and the two-stage models of the $\mathrm{AB}$, in that processing resources should be reallocated earlier if $T 1$ is processed more quickly. This result could also lead to an explanation of why Shapiro et al. (1994) failed to find an effect on the $A B$ when the target task requirement was changed from identification of an unknown target to mere detection of a prespecified target. If detection of target features triggers an identification response and target identification diverts processing resources from identifying later items, it should not matter whether T1 identification is required or not. The mere occurrence of an item to be detected results in similar demands on limitedcapacity attentional mechanisms, resulting in posttarget deficits. The greater the processing difficulty of $\mathrm{T} 1$, the longer limited resources will be unavailable for $\mathrm{T} 2$ processing, decreasing the probability that $\mathrm{T} 2$ will be reported accurately--that is, the attentional gate will be shut longer, according to Raymond et al. (1992), or Stage 2 processing of $\mathrm{T} 2$ will be delayed or eliminated, according to Chun and Potter (1995). The results from Experiments 1 and 2 were in accord with these predictions: Decreasing the amount of information provided about the target (defining the target in terms of its physical characteristics, as compared with defining it in terms of its identity and physical characteristics) pushed the response distribution further away from the target in the same-stream condition.

The results of Experiment 1 showed that, if a target word is known in advance, the word following it in the same stream is the most likely one to be reported. However, if the target is unknown but marked by a physical feature (uppercase vs. a lowercase stream), the response tendency is delayed to the third item after the target, on average. In Experiment 2, response tendencies were moved closer to the target if a subsequent word was highly related to the target, indicating that a word is more available as a response if it is semantically related to the preceding target. This result also supports the idea that the initial target is identified, even though target identification is unnecessary for reporting the following word in our task. Earlier studies of the $\mathrm{AB}$ have shown that the target and the item immediately following it are likely to be processed together, since the probability of reporting the probe is relatively high when it appears in the $T+1$ position (Chun \& Potter, 1995; Raymond et al., 1992). Therefore, for same-stream, early-associate conditions in Experiment 2 , it is likely that the target and the $T+1$ item were processed together and that the identification of both was facilitated by the semantic relationship between them. Since the presence of the $T+1$ item is presumably responsible for producing the $\mathrm{AB}$ deficit and the deficit itself is more apparent in items after $T+1$, we varied the lag between $T 1$ and $T 2$ items in Experiment 3, as in typical AB experiments (Chun \& Potter, 1995; Raymond et al., 1992).

The results from Experiments 2 and 3 indicate that the $A B$ occurs after a level at which some semantic analysis of the incoming items has occurred; items were more likely to be given as responses if they were semantic associates of the target than if they were not. These results strongly disconfirm the inhibition model (Raymond et al., 1992). The inhibition model proposes that, since items beyond $\mathrm{T} 1+1$ receive little, if any, processing until after the identification of $\mathrm{T} 1$, there should have been no difference in the probability of correct reports of $\mathrm{T} 2$ in the semantically related and unrelated conditions, especially at short lags. That is, the inhibition model predicts an interaction between lag and priming effects on the proportion of $\mathrm{T} 2$ items identified. This interaction failed to reach significance in Experiment 3, suggesting that word identity information is available during the $\mathrm{AB}$ period.

The idea that the identity of several items other than the target in the RSVP stream is available is supported by studies requiring the identification of either one or two 
targets (Botella \& Eriksen, 1992; Chun, Bromberg, \& Potter, 1994). In an experiment by Botella and Eriksen, participants were required to indicate the identity of a target letter appearing in a specific color by choosing from a list of response alternatives presented at the end of the trial. When the target letter was not among the alternatives presented, participants were more likely to choose items that had been presented in the stream than items that had not been presented, indicating that items other than the target had been identified. Chun et al. observed that the probability of a correct $T 2$ report was higher when the targets and the distractors belonged to dissimilar semantic categories, such as birds and fruits, than when they belonged to similar categories, such as birds among fourfooted animals. Since the similarity of targets and distractors was at a conceptual level in their task, any effects of similarity must have occurred after relatively deep processing of both targets and distractors.

The findings from the present studies can be explained by the interference model (Shapiro et al., 1994) and the two-stage model (Chun \& Potter, 1995). According to the interference model, most items, including T2, are identified, but only those items that match the internal templates for targets and those items immediately following them are selected for entry into VSTM. The AB deficit results from interference among items in the VSTM during retrieval and response stages. According to the twostage model, the presentation of any item in an RSVP stream activates a short-lived representation of its types, including some semantic information. The $\mathrm{AB}$ deficit occurs when T2's types do not survive long enough to gain entry to the tokenization stage. One prediction of both models, that the size of the $\mathrm{AB}$ deficit should be lower when the targets and the distractors, or the targets and their adjacent items, are dissimilar has been supported by several studies (Chun \& Potter, 1995; Isaak \& Shapiro, 1996; Raymond et al., 1995). The results from the present experiments contradict the idea that $A B$ deficits occur early in visual processing, and they strongly suggest that such deficits occur after the words have been identified.

According to Chun and Potter (1995; see also Chun, 1997), the speed of $T 1$ tokenization is dependent on the distinctiveness of T1's types, relative to those of the distractors. In Experiment 1, knowledge of T1 resulted in earlier reports of posttarget items in the same-stream condition. The two-stage model explains this result by enabling prior T1 knowledge to prime T1's types, leading to faster T1 tokenization. In the different-stream condition, however, there was little difference in the effects of three different levels of T1 knowledge. This result can be explained by assuming that spatial switching takes more time than T1 tokenization, minimizing the effect of tokenization speed.

In Experiment 2, $\mathrm{T} 2$ was more likely to be reported when T1 was a high semantic associate, at least in the earlyassociate condition. This result can be explained by as- suming that the type codes of items occurring in the attended spatial location are activated automatically in Stage 1 of Chun and Potter's (1995) model. As T1 is being tokenized, its types prime T2's types, making them more distinct, thereby increasing the probability of tokenization and report of T2. In Experiment 3, T2 was more likely to be reported when it occurred at longer lags after $\mathrm{T} 1$ and when it was a semantic associate of $\mathrm{T} 1$, and these two effects combined additively. These results can be explained by assuming that, as T1 tokenization nears completion, the threshold for tokenization of following items is lowered. The probability that a following item will pass this threshold and begin tokenization is dependent on the distinctiveness of its types. In both stream conditions, T2's types were made more distinctive through top-down priming.

If the $A B$ is caused solely by $T 1$ 's processing demand for limited resources, one could ask why the differentstream condition showed a larger posttarget deficit than did the same-stream condition in Experiment 3. Weichselgartner and Sperling (1987) explained that the posttarget deficit is due to two overlapping attentional events. The first event is signaled by $\mathrm{T} 1$ (or cue) and is rapidly extinguished when it is detected. The second event is launched to help identify later items. In the same-stream condition, both events occur in the same location and overlap in time, whereas in the different-stream condition, the first event is limited to the $T 1$ stream, and the second event is directed to the other stream. In the same-stream condition, immediate posttarget items are often reported, presumably because they fall within the first attentional event before it is terminated. Posttarget items in the different-stream condition are processed only by the second attentional event.

The inadequacy of Weichselgartner and Sperling's (1987) model of the AB is not that it is ineffective in explaining differences between results from same-stream and different-stream conditions but, rather, that it has difficulties explaining the effects of posttarget manipulations (e.g., a posttarget blank greatly reduces the AB; Raymond et al., 1992). Weichselgartner and Sperling's (1987; see also Sperling \& Weichselgartner, 1995) episodic theory of attention might be a good starting point for describing how attention selects spatial locations. In single-stream tasks, the attentional gate might remain open continuously, with perhaps some attenuation between $\mathrm{T} 1$ and $\mathrm{T} 2$. In different-stream tasks, the attentional gate gradually closes after $\mathrm{T} 1$ occurs in its stream, and then it gradually opens in the other stream, leading to a T2 deficit while this change is taking place. Chun and Potter's (1995) twostage model provides a parsimonious account of the $\mathrm{AB}$ effect in single-stream tasks. A model of attention that combines an early spatial selection mechanism with Chun and Potter's two-stage model can account for all of the results reported here.

The idea that all items' types are automatically activated when attending to a single RSVP stream is supported by 
Maki et al. (1997). They showed that when a distractor was a high associate of $\mathrm{T} 2$, it could prime $\mathrm{T} 2$ even when presented at lags between $T 1$ and $T 2$ that should result in an $\mathrm{AB}$ deficit for processing the distractor prime. This result suggests that semantic information is available from items processed during the $\mathrm{AB}$, a result congruent with Chun and Potter's (1995) two-stage model.

A similar conclusion was reached by Luck, Vogel, and Shapiro (1996), who used electrophysiological recordings of event-related potentials to measure the depth to which words in an RSVP stream were processed. Participants were given a context word to start each trial, which included a target somewhere in the stream, followed by a probe that could be related or unrelated to the context word. They used the N400 wave as an index of the degree of mismatch between a word and its context and showed that, even though the probe was often missed if it followed the target closely in the stream, the N400 waveform was unaffected by target-probe lag. This result is consistent with the idea that words occurring in the $A B$ period are processed to a semantic level but that their identities can be lost during a postperceptual stage of processing.

\section{REFERENCES}

Biederman, I., Glass, A. L., \& Stacy, E. W. (1973). Searching for objects in real-world scenes. Journal of Experimental Psychology, 97, 22-27.

Botella, J., \& Eriksen, C. W. (1992). Filtering versus parallel processing in RSVP tasks. Perception \& Psychophysics, 51, 334-343.

BreitMEYER, B. G., \& GANZ, L. (1976). Implications of sustained and transient channels for theories of visual pattern masking, saccadic suppression, and information processing. Psychological Review, 83, $1-36$.

BroadBent, D. E. (1977). The hidden preattentive processes. American Psychologist, 32, 109-118.

Broadbent, D. E., \& Broadbent, M. H. P. (1987). From detection to identification: Response to multiple targets in rapid serial visual presentation. Perception \& Psychophysics, 42, 105-113.

ChEal, M. L., \& LyON, R. D. (1991). Central and peripheral precuing of forced-choice discrimination. Quarterly Journal of Experimental Psychology, 43A, 859-880.

CHun, M. M. (1997). Types and tokens in visual processing: A double dissociation between the attentional blink and repetition blindness. Journal of Experimental Psychology: Human Perception \& Performance, 23, 738-755.

Chun, M. M., Bromberg, H. S., \& PotTer, M. C. (1994, November). Conceptual similarity between targets and distractors in the attentional blink. Paper presented at the 35th Annual Meeting of the Psychonomic Society, St. Louis.

Chun, M. M., \& Potter, M. C. (1995). A two-stage model for multiple target detection in RSVP. Journal of Experimental Psychology: Human Perception \& Performance, 21, 109-127.

DunCan, J., \& Humphreys, G. (1989). Visual search and stimulus similarity. Psychological Review, 96, 422-458.

EgLy, R., \& Homa, D. (1991). Reallocation of visual attention. Journal of Experimental Psychology: Human Perception \& Performance, 17, 142-159.

ENGLE, F. L. (1971). Visual conspicuity, directed attention, and retinal locus. Vision Research, 11, 563-576.

Eriksen, C. W., \& Collins, J. F. (1969). Temporal course of selective attention. Journal of Experimental Psychology, 80, 254-261.

Gathercole, S. E., \& Broadbent, D. E. (1984). Combining attributes in specified and categorized target search: Further evidence for strategic differences. Memory \& Cognition, 12, 329-337.

IsAAK, M. I., \& SHAPIRO, K. L. (1996, October). The attentional blink reflects retrieval competition among categorically similar targets. Paper presented at the 37th Annual Meeting of the Psychonomic Society, Chicago.

JAMES, W. (1890). Principles of psychology. New York: Holt.

JUOLA, J. F. (1988). The use of computer displays to improve reading comprehension. Applied Cognitive Psychology, 2, 87-95.

Juola, J. F., Bouwhuis, D. G., CoOper, E. E., \& Warner, C. B. (1991). Control of attention around the fovea. Journal of Experimental Psychology: Human Perception \& Performance, 17, 125-141.

Juola, J. F., Koshino, H., \& Warner, C. B. (1995). Tradeoffs between attentional effects of spatial cues and abrupt onsets. Perception \& Psychophysics, 57, 333-342.

JuOLA, J. F., WARD, N. J., \& MCNAmara, T. (1982). Visual search and reading of rapid, serial visual presentations of letter strings, words, and text. Journal of Experimental Psychology: General, 111, 208227.

KuČERA, H., \& FranCIS, W. (1967). Computational analysis of presentday American English. Providence, RI: Brown University Press.

LABERGE, D. (1995). Attentional processing. Cambridge, MA: Harvard University Press.

LofTus, G. R., \& MaCkworth, N. H. (1978). Cognitive determinants of fixation locations during picture viewing. Journal of Experimental Psychology: Human Perception \& Performance, 4, 565-572.

LuCK, S. J., Vogel, E. K., \& SHapiRo, K. L. (1996). Word meanings can be accessed but not reported during the attentional blink. Nature, 386, 616-618.

Maki, W. S., Frigen, K., \& Paulson, K. (1997). Associative priming by targets and distractors during rapid serial visual presentation: Does word meaning survive the attentional blink? Journal of Experimental Psychology: Human Perception \& Performance, 23, 10141034.

MÜLLER, H. J., \& RABBITT, P. M. (1989). Reflexive and voluntary orienting of visual attention: Time course of activation and resistance to interruption. Journal of Experimental Psychology: Human Perception \& Performance, 15, 315-330.

Nelson, D. L., McEvoy, C. L., \& Schreiber, T. (1993). The University of South Florida word association, rhyme, and word fragment norms. Unpublished manuscript.

Palmer, S. E. (1975). Visual perception and world knowledge: Notes on a model of sensory-cognitive interaction. In D. A. Norman \& D. E. Rumelhart (Eds.), Explorations in cognition (pp. 279-307). San Francisco: Freeman.

PosNer, M. I. (1980). Orienting of attention. Quarterly Journal of Experimental Psychology, 32, 3-25.

Posner, M. I., Snyder, C. R. R., \& Davidson, B. J. (1980). Attention and the detection of signals. Journal of Experimental Psychology: General, 109, 160-174.

Raymond, J. E., Shapiro, K. L., \& ARnell, K. M. (1992). Temporary suppression of visual processing in an RSVP task: An attentional blink? Journal of Experimental Psychology: Human Perception \& Performance, 18, 849-860.

Raymond, J. E., Shapiro, K. L., \& ARnell, K. M. (1995). Similarity determines the attentional blink. Journal of Experimental Psychology: Human Perception \& Performance, 21, 653-662.

RAYNER, K. (1983). The perceptual span and eye movement control in reading. In K. Rayner (Ed.), Eye movements in reading (pp. 97-128). New York: Academic Press.

ReEves, A., \& SPERLING, G. (1986). Attention gating in short-term visual memory. Psychological Review, 93, 180-206.

Shapiro, K. L., Driver, J., Ward, R., \& Sorensen, R. E. (1997). Priming from the attentional blink: A failure to extract visual tokens but not visual types. Psychological Science, 8, 95-100.

Shapiro, K. L., Raymond, J. E., \& Arnell, K. M. (1994). Attention to visual pattern information produces the attentional blink in RSVP. Journal of Experimental Psychology: Human Perception \& Performance, 20, 357-371. 
SPERLING, G. (1960). The information available in brief visual presentation. Psychological Monographs, 74(11, Whole No. 498).

SPERLING, G., \& WEICHSELGARTNER. E. (1995). Episodic theory of the dynamics of spatial attention. Psychological Review, 102, 503-532.

Theeuwes, J. (1996). Perceptual selectivity for color and form: On the nature of the interference effect. In A. F. Kramer, M. G. H. Coles, \& G. D. Logan (Eds.), Converging operations in the study of visual selective attention (pp. 297-314). Washington, DC: American Psychological Association.

Treisman, A., \& Gelade, G. (1980). A feature integration theory of attention. Cognitive Psvchology, 12, 97-136.

VAN DER HEIJDEN, A. H. C. (1992). Selective attention in vision. London: Routledge.
VON WRIGHT, J. M. (1972). On the problem of selection in iconic memory. Scandinavian Journal of Psychology, 13, 159-171.

Weichselgartner, E., \& SPERLing, G. (1987). Dynamics of automatic and controlled visual attention. Science, 238, 778-780.

YANTIS, S., \& JONIDES, J. (1990). Abrupt visual onsets and selective attention: Voluntary versus automatic allocation. Journal of Experimental Psychology: Human Perception \& Performance, 16, 121-134.

(Manuscript received June 24, 1998; revision accepted for publication March 29, 1999.) 